\title{
Design and Realization of an Isolated DC-DC Converter with Regenerative Snubber circuit using Tertiary Winding Transformer
}

\author{
Lakshmi $\mathrm{S}^{1}$, Karthikeyan $\mathrm{B}^{2}$, Vinoth KumarP $\mathrm{K}^{3}$ \\ \{lakshmi.eee@bharathuniv.ac.in ${ }^{1}$, karthikeyanb@saec.ac.in ${ }^{2}$,vinothkumarp@skcet.ac.in ${ }^{3}$ \} \\ Bharath Institute of Higher Education and Research, Chennai - $600073^{1}$, S. A. Engineering College, \\ Chennai $600077^{2}$, Sri Krishna College of Engineering and Technology, Coimbatore 641008
}

\begin{abstract}
A novel isolated dc-dc forward converter with a regenerative snubber circuit is introduced in this paper. Regenerative operation is achieved by effective utilization of the tertiary winding transformer. Due to easy control of the turn's ratio of the transformer, the capacitor gets easily charged which in turn improves the overall efficiency of the converter. The performance of the circuit is analyzed by simulation and using hardware. The proposed converter also achieves ZVS without any additional circuitry
\end{abstract}

Keywords: Forward Converter, snubber circuit, zero voltage switching, dc-dc converter, tertiary winding.

\section{Introduction}

The forward converter is type of dc-dc converter that steps up or steps down the voltage based on the transformer turns ratio and also provides galvanic isolation for the load [1]. It performs the same operation as the fly back converter, but is generally more energy efficient. Two types of converter with galvanic isolation are Flyback converter and Forward converter. Forward converter is one of the classification of SMPS that provides a constant and controlled dc output. The gyrator model and its corresponding equivalent circuit model of the integrated transformer is derived. Three transformers wounded on a single core forms the transformer. Wide ranges of output voltage, reduced ripples, faster response are some of the highlights of the converter and hence it is highly suitable for low voltage and high current applications [2].

In forward converter topology described in [3], without utilization of a active switch, just by the use of the snubber circuit in the primary side, efficiency has been improved. The converter has an output for $40 \mathrm{~W}$ with a maximum efficiency of $91 \%$ producing $3 \mathrm{~V}$ and $4 \mathrm{~A}$ at the output which is best suitable for telecommunication systems. Theoretical analysis on an unique topology of forward converter with two diodes that realizes magnetizing reset recycling magnetizing energy is proposed. Here the transformers are parallel connected such that the power losses are equally distributed. It also uses interleaving architecture such that current ripple at the output side is minimized with maximum power density [4]. Nevertheless the voltage stress causes more losses in the circuit, hence [5] examined the parameters that 
affect the clamp voltage and from which critical parameters are identified and arrived at a mathematical solution for the clamp voltage. In [6], author designed a snubber circuit which is composed of inductance, capacitance and diodes which is basically non-dissipative instead of using capacitors and resistors. The non-dissipative feature reduces the switching loss of the converter. The working operation of a forward converter with LC snubber is studied and the energy loss is evaluated. Based on the resultant values, the design of snubber circuit is carefully undergone to reduce the losses which are explained in [7]. The converter proposed operates at high switching frequencies with wide operating ranges of voltage and power. Effect of voltage spikes and losses due to residual energy is investigated for a RCD snubber circuit. The selection of resistor in RCD snubber is performed by a new design procedure to make an optimal commutation between CM noises and losses [8].

Various features of a forward converter with energy saving snubber circuit for different topologies have been discussed by various authors. It can be observed that reduced ripples and low power loss can be obtained however there is still the presence of voltage spikes, higher $\mathrm{dv} / \mathrm{dt}$ which is mainly due to the leakage reactance in the transformer that causes more power loss. In this paper a new topology of forward converter with same snubber circuit but with tertiary winding transformer is proposed. Hence due to the tertiary winding the loss due to leakage reactance is much reduced.

\section{Text formatting}

The objective of the project is to design, simulate and implementing forward converter with regenerative snubber.

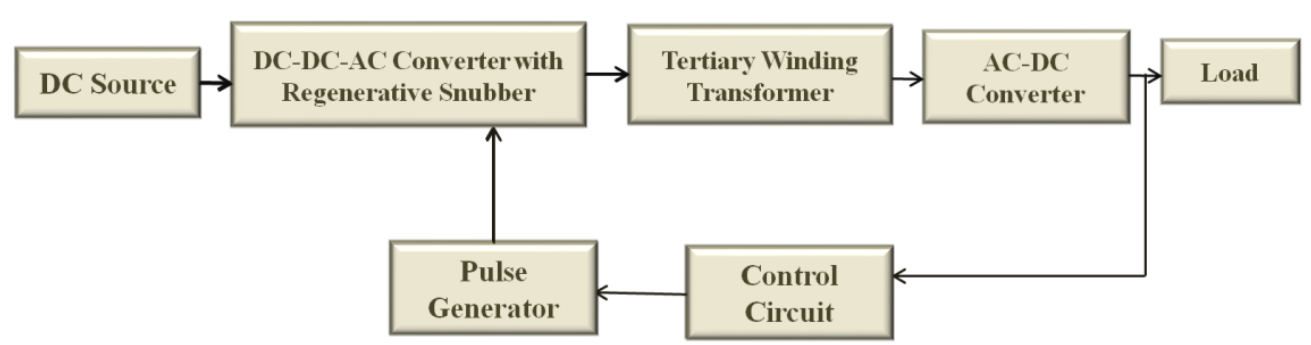

Fig. 1.Block diagram of the proposed forward converter

The circuit diagram of the forward converter with regenerative snubber and tertiary winding is shown below.

Diode, capacitor and tertiary transformer winding forms the snubber circuit. Transformer core and winding polarity arrangement are the arrangements that make the forward converter different from a Flyback converter. The conduction of the input and output is also different in both the converters. 


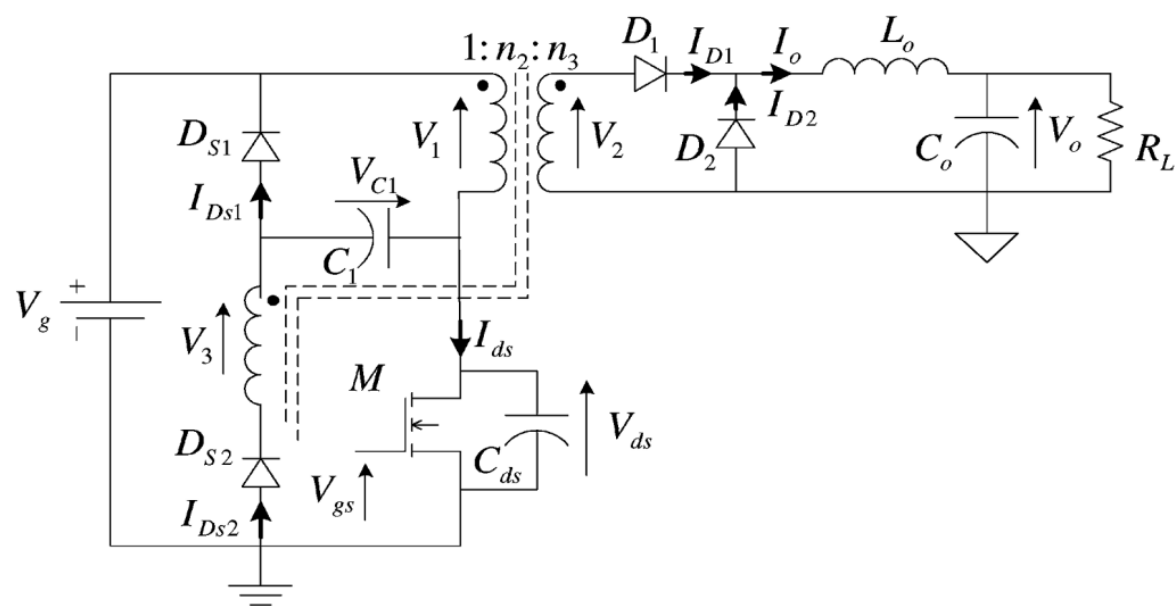

Fig. 2. Circuit diagram of the proposed Forward converter regenerative snubber

\section{OPERATION OF FORWARD CONVERTER}

The transformer is central to analyzing the operation of the forward converter with the proposed regenerative snubber. The analysis to follow relies on the three winding transformer model, shown in Fig. Here, the transformers 'magnetizing and the leakage inductances are all referred to the primary.

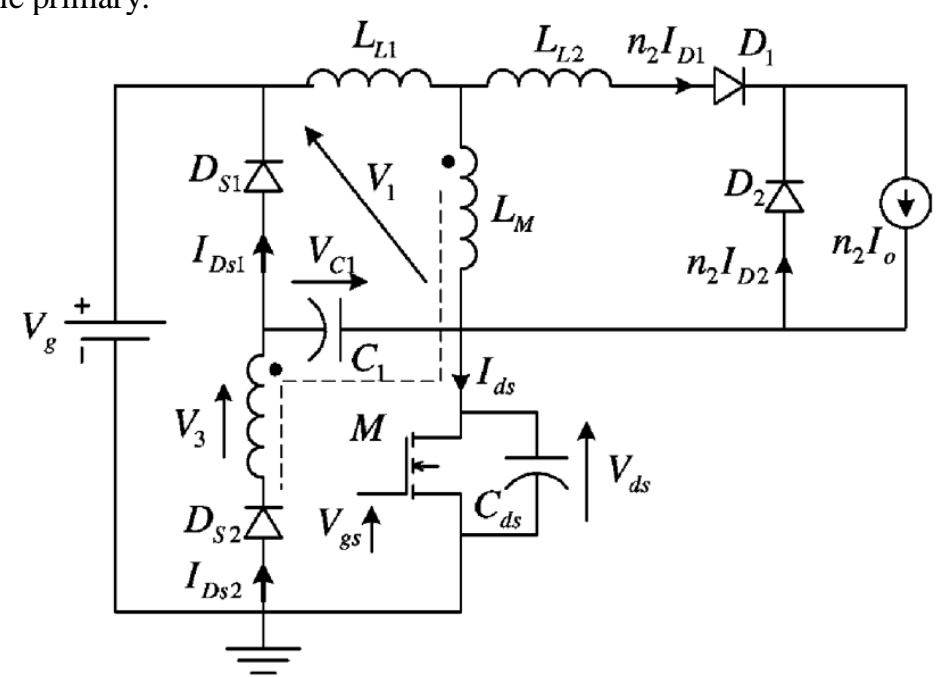

Fig. 3. Equivalent circuit of the forward converter with regenerative snubber

The equivalent circuit explains the effect of transformer leakage reactance on the circuit. Resonance condition appears on the transformer inductance and snubber capacitance. The circuit operates in different modes of operation that are functions of duty cycle and the switching frequency. 


\section{DESCRIPTION - MODES OF OPERATION}

Mode $1\left(t_{0}-t_{1}\right)$ : This mode gets initiated by turning ON the power switch. Voltage is fed to the primary winding of the transformer by turning on the power switch. In this mode the diode $D_{2}$ is turned on and diode $D_{1}$ is off. Now the capacitor discharges its stored energy to the tertiary winding through the diode $\mathrm{D}_{\mathrm{S} 2}$. The energy gets transferred to the capacitor $\mathrm{C}_{1}$ as the reactance at $L_{L 1}$ and $L_{L 3}$ resonates. Now there is a polarity change in the capacitor $C_{1}$ and $D_{1}$ turns ON.
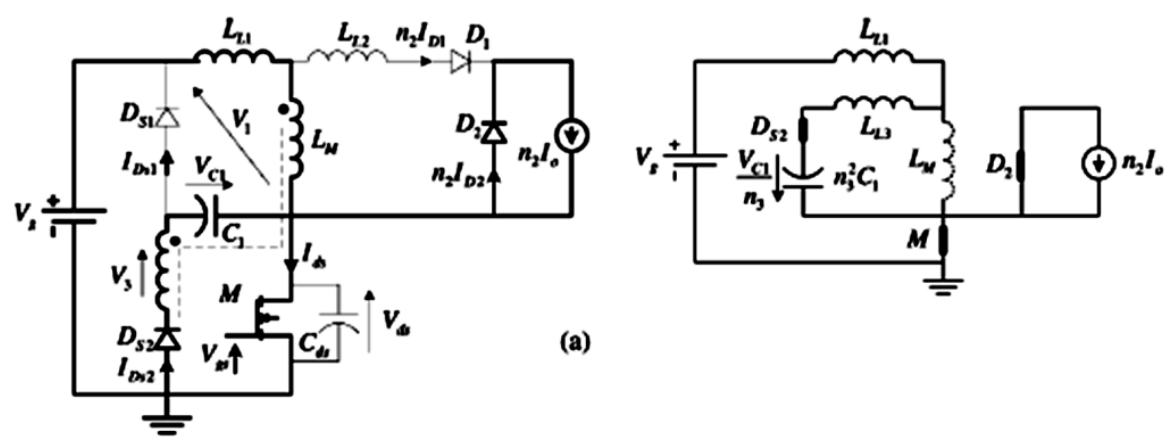

(a)

Fig. 4. Equivalent circuit in Mode 1

Mode $2\left(\mathrm{t}_{1}-\mathrm{t}_{2}\right)$ : This mode initiates when $\mathrm{D}_{1}$ turns on. Resonant condition occurs in all three inductance. This mode continues to be active till the capacitor $C_{1}$ voltage reaches $-V_{g}$. In this condition diode locks the voltage across $\mathrm{C}_{1}$. At this condition, the inductance stores the excess energy. Capacitor $C_{1}$ gets charged by clamping the snubber capacitor which exhibits zero voltage turn off in the power switch.
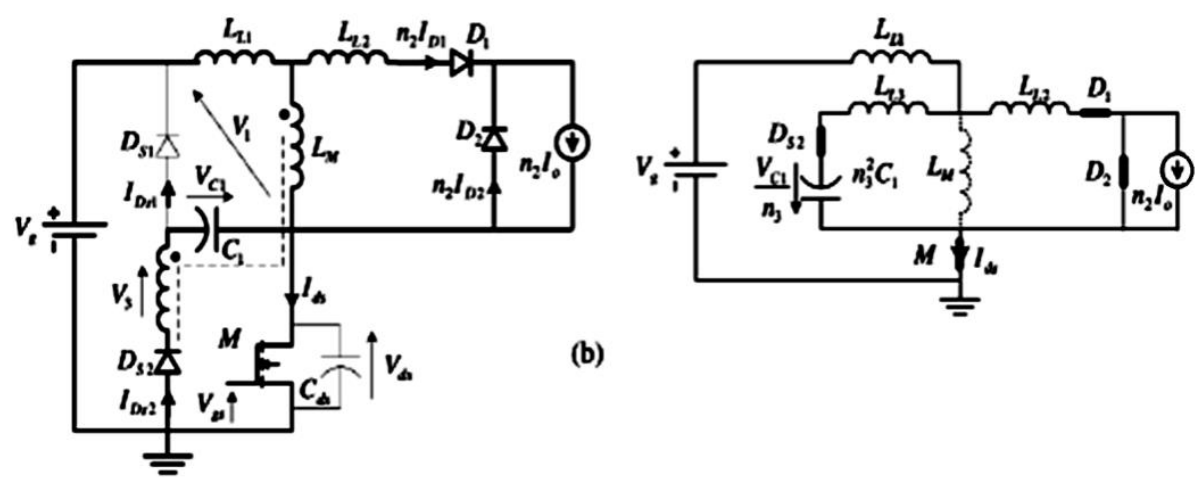

(b)

Fig. 5.Equivalent circuit in Mode 2 
Mode $3\left(t_{3}-t_{4}\right)$ : This mode initiates when the snubber diodes $D_{\mathrm{S} 1}$ and $D_{\mathrm{S} 2}$ is turned on such that there exists a current flow path for the winding to the supply. Now in this condition, the supply voltage appears across the transformer winding. The turns ratio of the transformer is less than one thus making the generated voltage higher than the source voltage. The stored energy in the leakage inductance is discharged to the source by the snubber circuit causing a regenerative action. In this condition, based on the turn's ratio the voltage across the secondary increases. Due to this, a voltage $\left(\mathrm{n}_{2} / \mathrm{n}_{3} * \mathrm{~V}_{\mathrm{g}}\right)$ appears across the diode $\mathrm{D}_{2}$. This mode continue till the energy stored in the inductance are completely discharged and the snubber diodes are turned off completely.
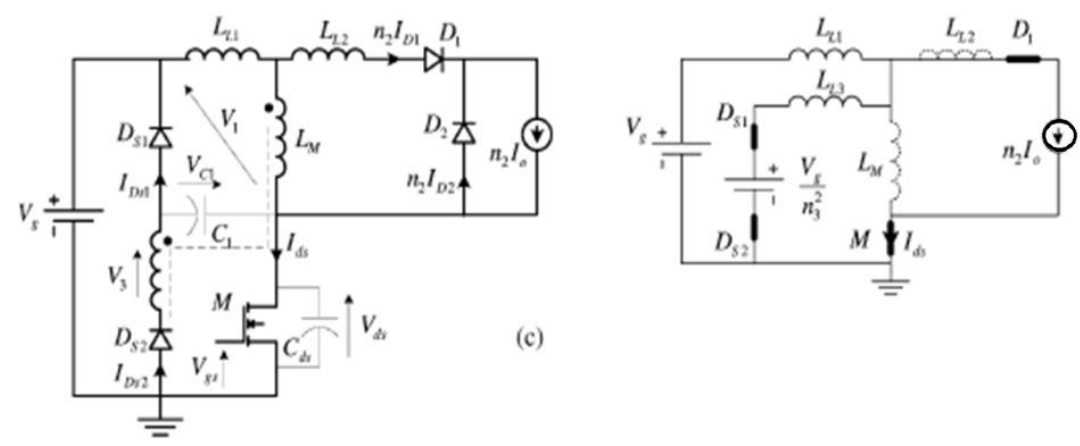

Fig. 6. Equivalent circuit in Mode 3

Mode $4\left(t_{4}-t_{5}\right)$ : In this mode, the diodes $D_{S 1}$ and $D_{S 2}$ are turned off. Figure 7 shows the equivalent circuit of the operating mode 4 . In this mode, transformer gets charged there is a ramp occurring in the magnetizing current. This mode is said to be active till the transistor is switched off by an external signal.
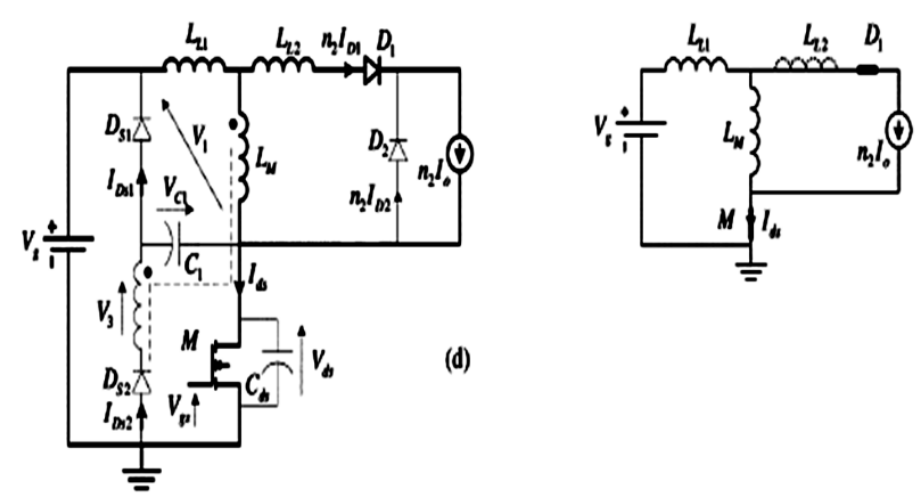

Fig. 7. Equivalent circuit in Mode 4

Mode $5\left(\mathrm{t}_{5}-\mathrm{t}_{6}\right)$ : This operating mode is active when the transistor is tuned off. Figure 8 shows the equivalent circuit for mode 5 . The diode $D_{S 1}$ is turned on by the magnetizing current of the transformer. In this mode the capacitor gets charged to $-\mathrm{V}_{\mathrm{g}}$ and thus turning off the power 
switch. Now the stored energy in $\mathrm{C}_{1}$ is released to the load by the magnetizing current. Due to the negative voltage across $C_{1}$, diode $D_{1}$ is in on condition as the load current flows through the primary winding of the transformer. Due to decrease in voltage across $\mathrm{C}_{1}$, switch capacitance $\mathrm{C}_{D S}$ voltage increases. This mode continues its operation till the voltage across the snubber capacitor $C_{1}$ reverses that makes diode $D_{2}$ to turn off. The snubber capacitance gets discharged easily under full load condition and the vice versa during light load condition.

$$
\mathrm{C}_{\mathrm{S}}=\mathrm{C}_{1}+\mathrm{C}_{\mathrm{DS}}
$$

$$
\Delta \mathrm{t}_{5} \leq \pi / 2 \sqrt{ }\left(\mathrm{L}_{\mathrm{m}}+\mathrm{L}_{\mathrm{L} 1}\right) \mathrm{C}_{\mathrm{S}}
$$
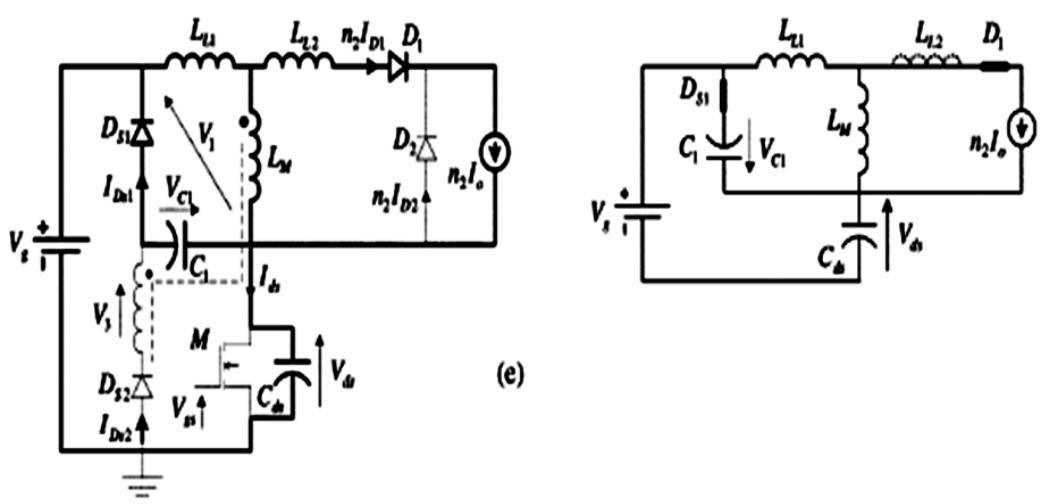

Fig. 8. Equivalent circuit in Mode 5

Mode $6\left(\mathrm{t}_{6}-\mathrm{t}_{7}\right)$ : In this mode the diode $\mathrm{D}_{2}$ is switched on. Figure 9 show the equivalent circuit in mode 6 . The magnetizing current of the transformer resonates between the capacitor $\mathrm{C}_{1}$ and $\mathrm{C}_{\mathrm{DS}}$ with the inductance $\mathrm{L}_{\mathrm{L} 1}$ and $\mathrm{L}_{\mathrm{L} 2}$ respectively. Under this condition, the current flowing through $\mathrm{D}_{1}$ decreases while $\mathrm{D}_{2}$ increases. This mode continues till $\mathrm{D}_{1}$ is switched off and $\mathrm{D}_{2}$ is switched on. Time taken for mode 6 operation is less than $1 / 4$ th of the leakage resonant period.

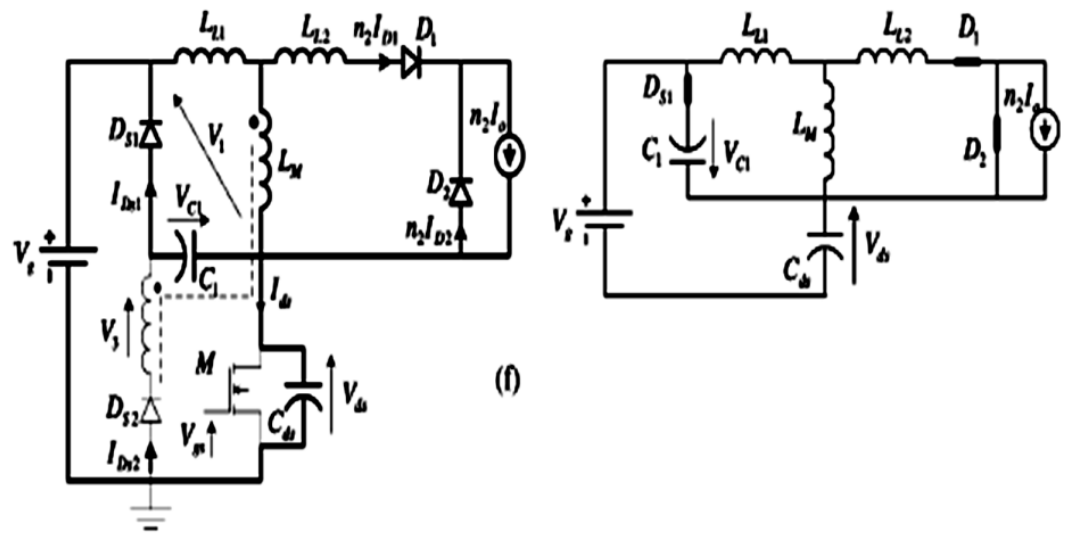

Fig. 9. Equivalent circuit in Mode 6 


$$
\mathrm{t}_{6}<\pi / 2 \sqrt{ }\left(\mathrm{L}_{\mathrm{L} 1}+\mathrm{L}_{\mathrm{L} 2}\right) \mathrm{Cs}_{\mathrm{S}}
$$

Mode $7\left(t_{7}-t_{8}\right)$ : This mode is active when the diode $D_{1}$ is turned off. Here the snubber capacitor $\mathrm{C} 1$ resonates with $\mathrm{C}_{\mathrm{DS}}$ and the inductance $\mathrm{L}_{\mathrm{L} 1}$ and the magnetizing inductance $\mathrm{L}_{\mathrm{m}}$. This mode continues to be active until the magnetizing current drops to zero and $\mathrm{D}_{\mathrm{S} 1}$ is switched off. Now the transformer is again reset to its initial condition once the energy in the magnetizing component is transferred to the snubber capacitance. This snubber capacitance $\mathrm{C}_{\mathrm{S}}$ resonates with the transformer inductance until it reaches $1 / 4$ th of the total resonant period. The duration of Mode 7 can be expressed as

$$
\Delta \mathrm{t}_{7} \approx \pi / 2 \sqrt{ }\left(\mathrm{L}_{\mathrm{m}}+\mathrm{L}_{\mathrm{L} 1} * \mathrm{~L}_{\mathrm{L} 2}\right) \mathrm{C}_{\mathrm{S}}(4)
$$
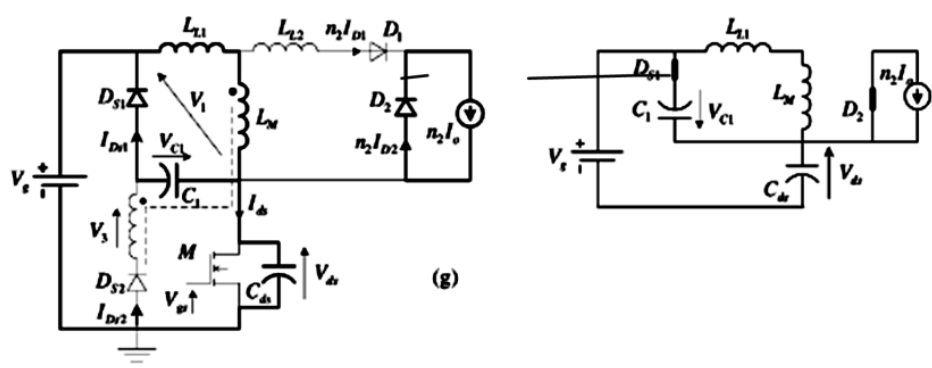

Fig. 10. Equivalent circuit in Mode 7

Mode $8\left(t_{8}-t_{9}\right)$ : In this mode the diode $D_{S 1}$ is switched off. Fig.11 shows its equivalent circuit. The capacitor $C_{D S}$ is completely charged till it reaches the supply voltage $V_{\mathrm{g}}$. In this mode there is a resonating condition between the capacitor $\mathrm{C}_{\mathrm{DS}}$, inductance $\mathrm{L}_{\mathrm{L} 2}$ and the magnetizing inductance $\mathrm{L}_{\mathrm{m}}$. At the same time, partial energy stored in $\mathrm{C}_{\mathrm{DS}}$ is fed to the source. This mode continues till the energy across the capacitance is reduced and diode $\mathrm{D}_{\mathrm{S} 1}$ starts to conduct. This mode operating duration is $1 / 4$ the total resonating period and the same is determined by the magnetizing inductance and capacitance $\mathrm{C}_{\mathrm{DS}}$.

$$
\Delta \mathrm{t} 8 \approx \pi / 2 \sqrt{ }\left(\mathrm{L}_{\mathrm{m}}+\mathrm{L}_{\mathrm{L} 2}\right) \mathrm{C}_{\mathrm{DS}}(5)
$$
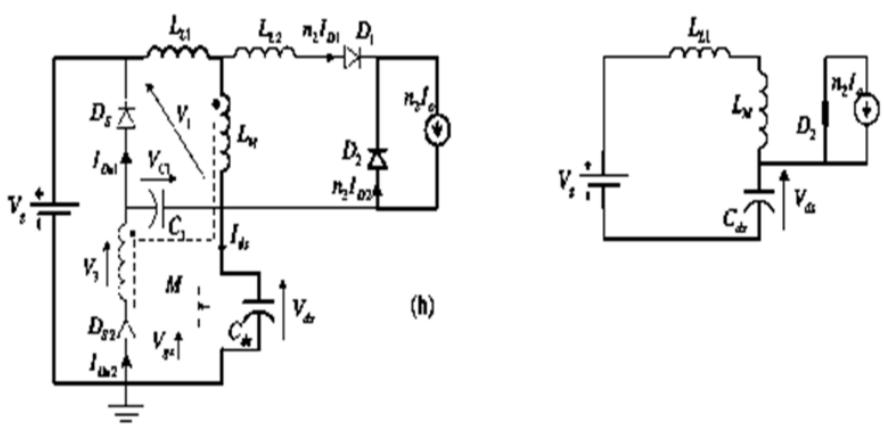

Fig. 11. Equivalent circuit in Mode 8 
Mode $9\left(\mathrm{t}_{9}-\mathrm{t}_{10}\right)$ : This mode gets active when diode $\mathrm{D}_{\mathrm{S} 1}$ is switched on. In this mode the stored energy of the snubber capacitance gets discharged through the transformer winding. The stored energy is fed to the source performing regenerative action. In this mode, the windings are in series thus making the equivalent inductance to be $\left(1+n_{3}\right)^{2} L_{m}$. This is the last operating mode for the proposed system. The figure 12 shows the equivalent circuit of the proposed system in Mode 9.
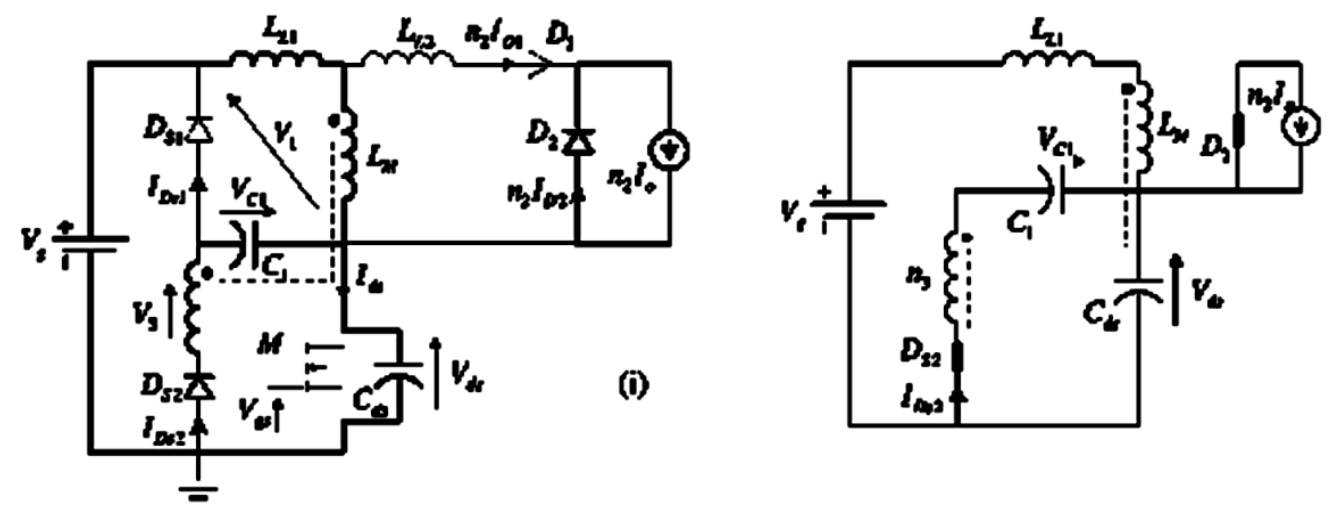

Fig. 12. Equivalent circuit in Mode 9

\section{4. a. SIMULATION FOR PROPOSED FORWARD CONVERTER-R LOAD}

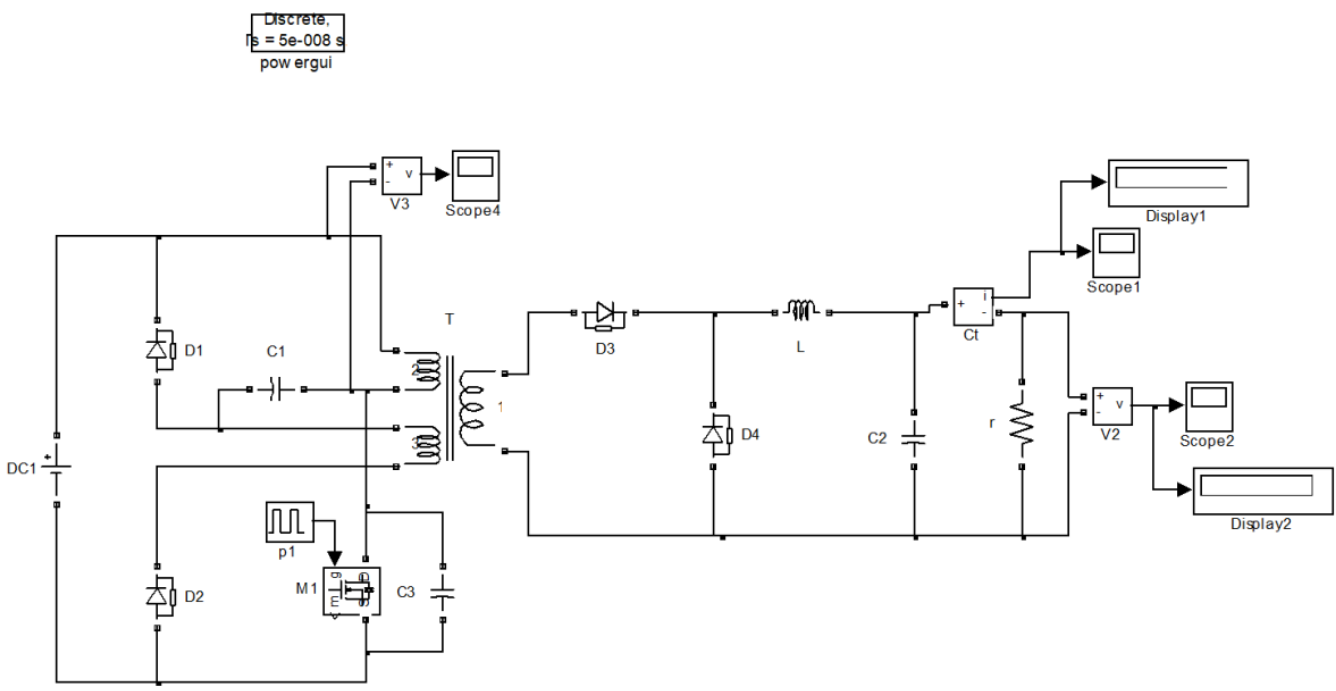

Fig. 13.Matlab simulation diagram for Proposed Circuit with R Load 


\section{4. b. Simulation results of the proposed system with $R$ load}

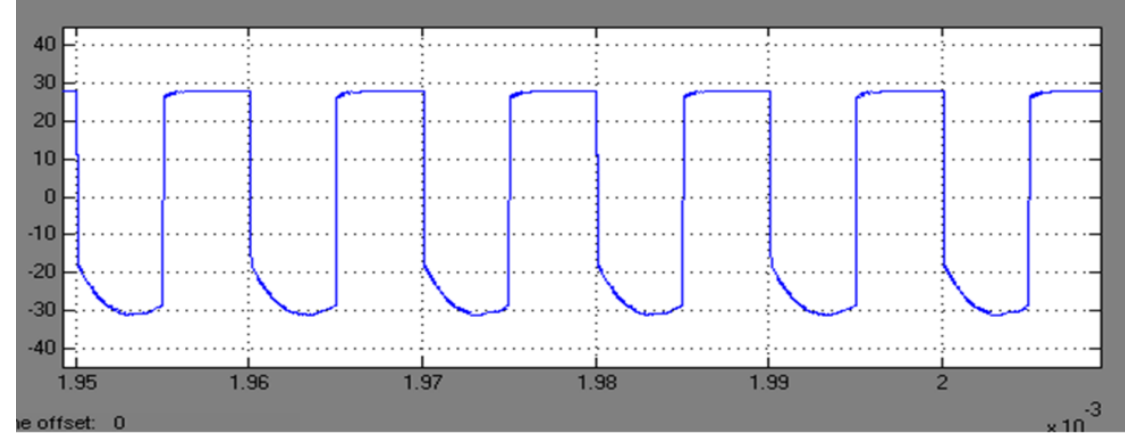

Fig 14.Simulated Results of the Output Voltage

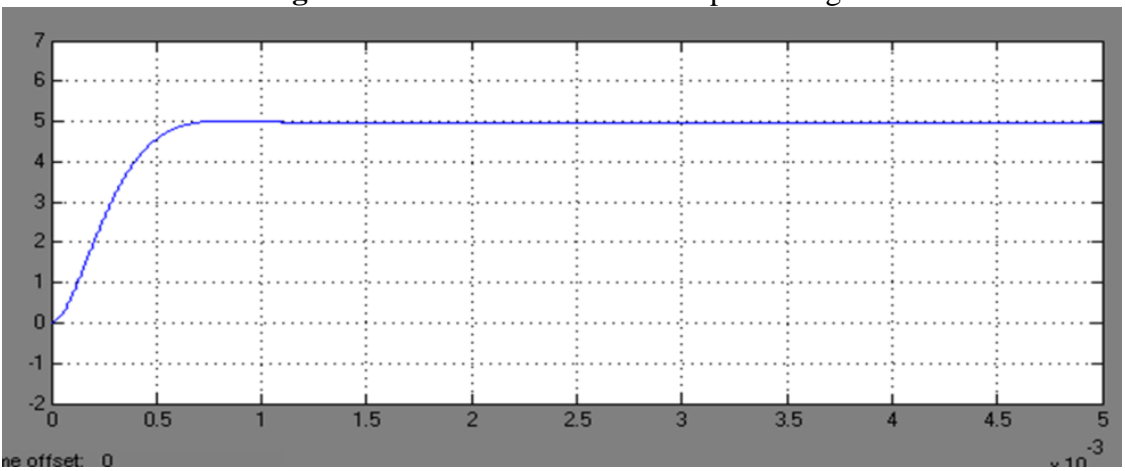

Fig. 15. Simulated Results for Output Current

4. c. Simulation model of the prposed circuit using motor load
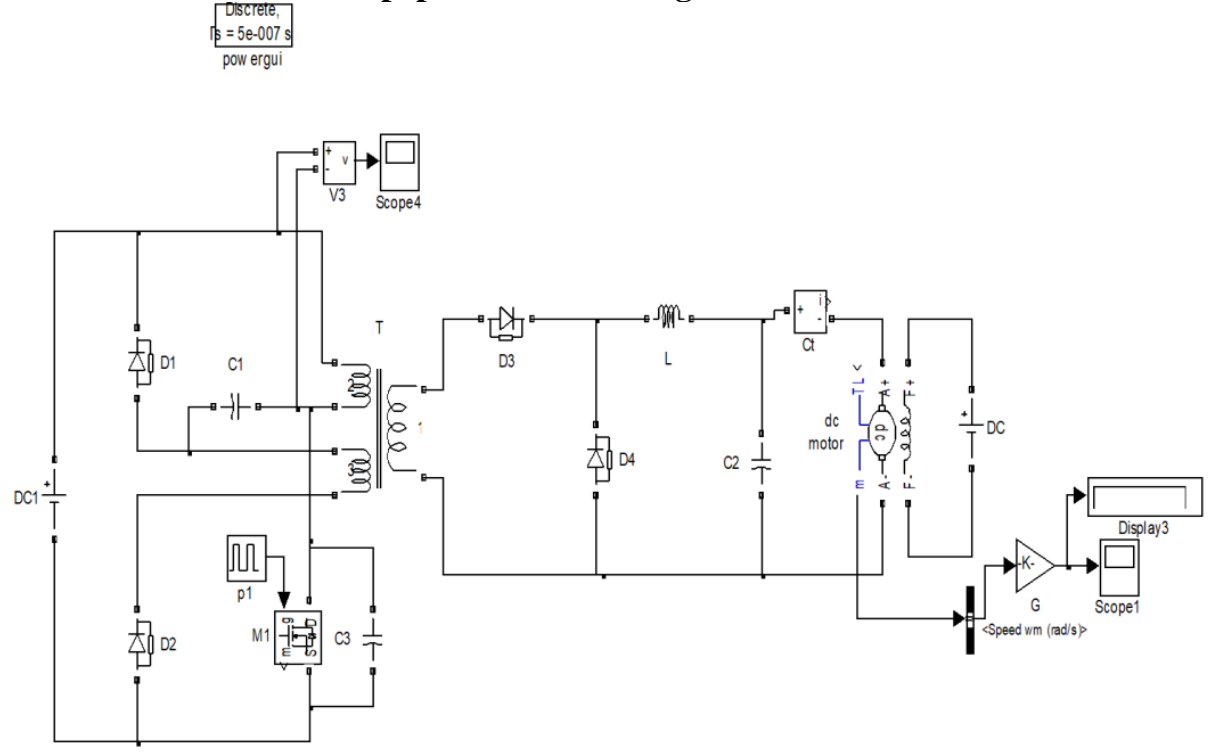

Fig. 16. Simulated models for forward converter with motor load 


\section{4. d. Simulation results of the proposed system with motor load}

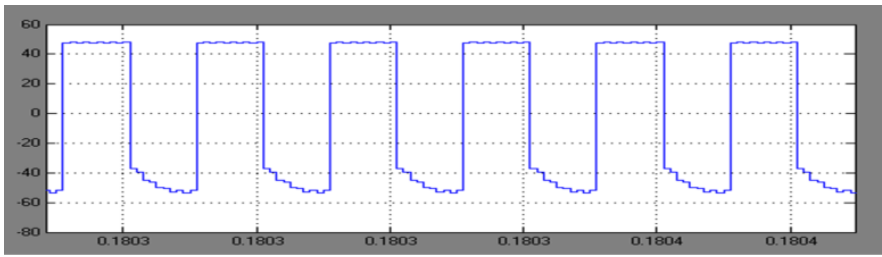

Fig. 17. Simulated results for inverter output voltage

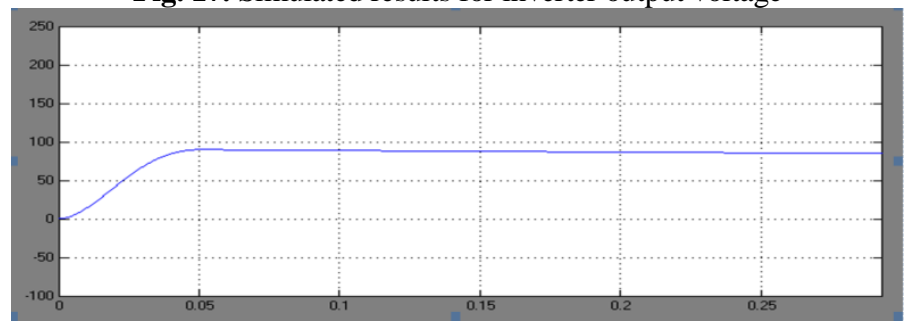

Fig. 18. Simulated results for armature speed

The output results for with conventional and proposed system is simulated using MATLAB. The results obtained through the simulation of proposed forward converter and conventional circuit using MATLAB is to be analyzed in this chapter.

\section{Comparison of Conventional And Proposed Circuit}

Figure 19 shows the comparison between the models. From the graph it is observed that the output power in proposed circuit is higher than the conventional one.

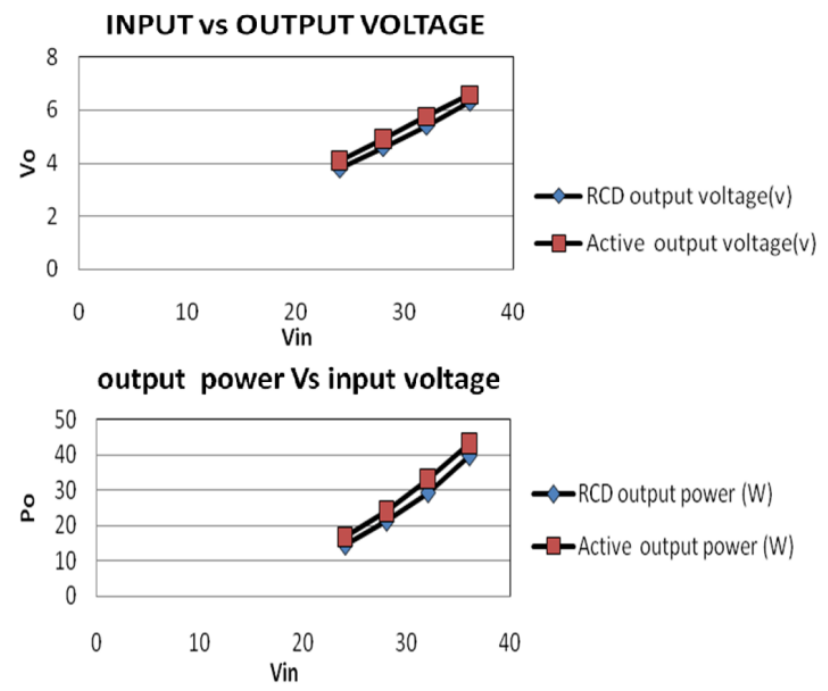

Fig. 19. Comparison of conventional and proposed circuit i/o voltages \& i/o power 
TABLE I. Comparison of output voltages \& power

\begin{tabular}{lllll}
$\begin{array}{l}\text { Input } \\
\text { voltage } \\
\text { (v) }\end{array}$ & $\begin{array}{l}\text { RCD output } \\
\text { voltage(v) }\end{array}$ & $\begin{array}{l}\text { Active output } \\
\text { voltage(v) }\end{array}$ & $\begin{array}{l}\text { RCD output } \\
\text { power (W) }\end{array}$ & $\begin{array}{l}\text { Active } \\
\text { output power } \\
(\mathrm{W})\end{array}$ \\
\hline 24 & 3.8 & 4.1 & 14.44 & 16.81 \\
\hline 28 & 4.6 & 4.9 & 21.16 & 24.1 \\
\hline 32 & 5.4 & 5.76 & 29.2 & 33.2 \\
\hline 36 & 6.3 & 6.57 & 39.6 & 43.2
\end{tabular}

\section{Design Details}

Flux of the motor used $\Phi=10 \mu w b$

Frequency $\mathrm{F}_{\mathrm{s}}=25 \mathrm{KHz}$

Output Voltage $\mathrm{V}_{\mathrm{o}}=5 \mathrm{~V}$

Input voltage $\mathrm{V}_{\text {in }}=28 \mathrm{~V}$

Output Current $\mathrm{I}_{\mathrm{o}}=5 \mathrm{~A}$

ripple factor $=4$ X10-5

\section{Transformer Design:(Ferrite core)}

Formulae used:

$\mathrm{E} 1=4.44 \mathrm{~N} 1 \Phi \mathrm{F}$

$\mathrm{E} 2=4.44 \mathrm{~N} 2 \Phi \mathrm{F}$

$\mathrm{E} 3=4.44 \mathrm{~N} 1 \Phi \mathrm{F}$

$\mathrm{N} 1=30$ TURNS

$\mathrm{N} 2=5$ TURNS

$\mathrm{N} 3=30$ TURNS

\section{Design of transformer leakage reactance}

$$
\begin{aligned}
& \mathrm{S}=\mathrm{L} / \mathrm{Au} \\
& \mathrm{S}=45^{*} 106 \\
& \mathrm{~L}_{\mathrm{L} 1}=\mathrm{N}_{2} / \mathrm{S} \\
& \mathrm{L}_{\mathrm{L} 2}=\mathrm{N}_{2} / \mathrm{S} \\
& \mathrm{L}_{\mathrm{L} 3}=\mathrm{N}_{2} / \mathrm{S}
\end{aligned}
$$

$\mathrm{R}_{\mathrm{L}}=\mathrm{V}_{0} / \mathrm{I}_{\mathrm{O}}$

Output Power:

$\mathrm{P}_{\mathrm{o}}=\mathrm{I}_{\mathrm{O} 2} * \mathrm{R}$

\section{Design of filter component:}

Ripple (r) $=1 / 4 \sqrt{ } 3 \mathrm{fC}_{\mathrm{R}}$

$\mathrm{C}=100 \mu \mathrm{F}$.

Ripple $(\mathrm{r})=\sqrt{ } 3 / \omega 2 \mathrm{LC}$

$\mathrm{L}=260 \mu \mathrm{H}$ 


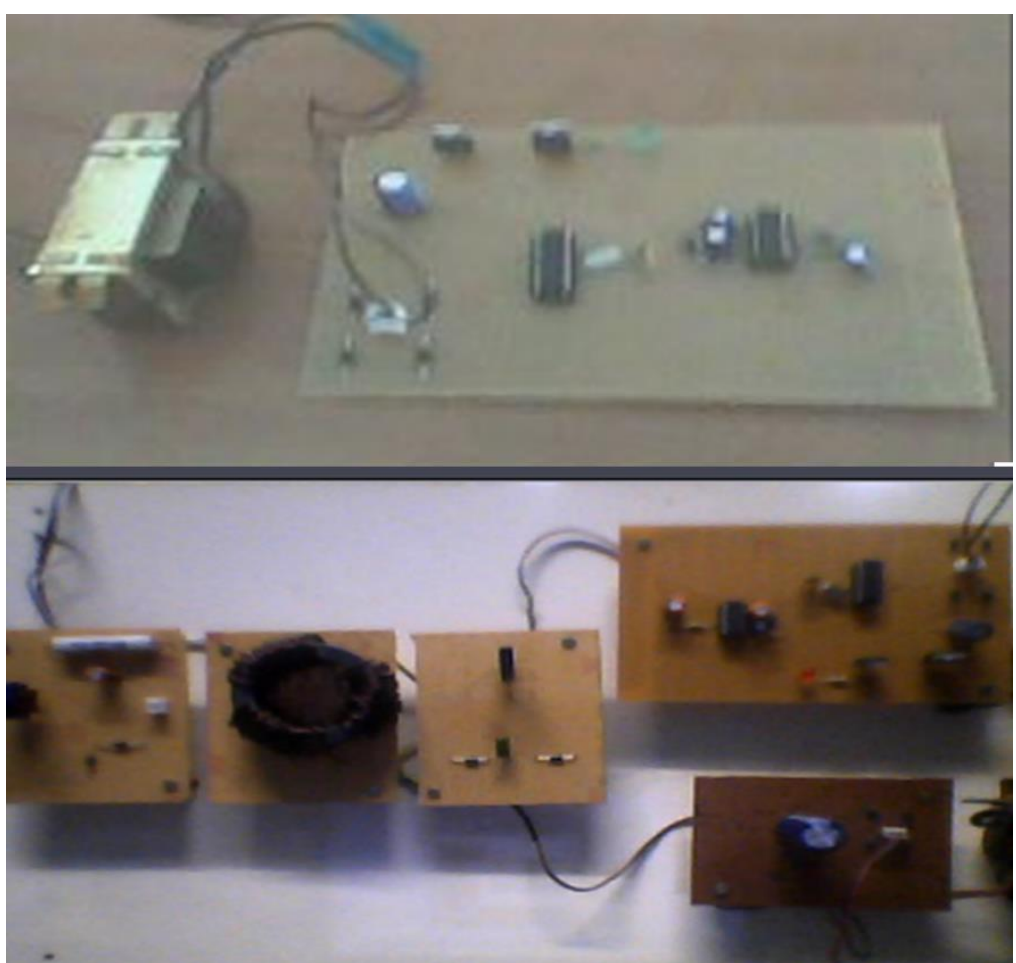

Fig. 20. Hardware implementation of the control circuit \& Power circuit

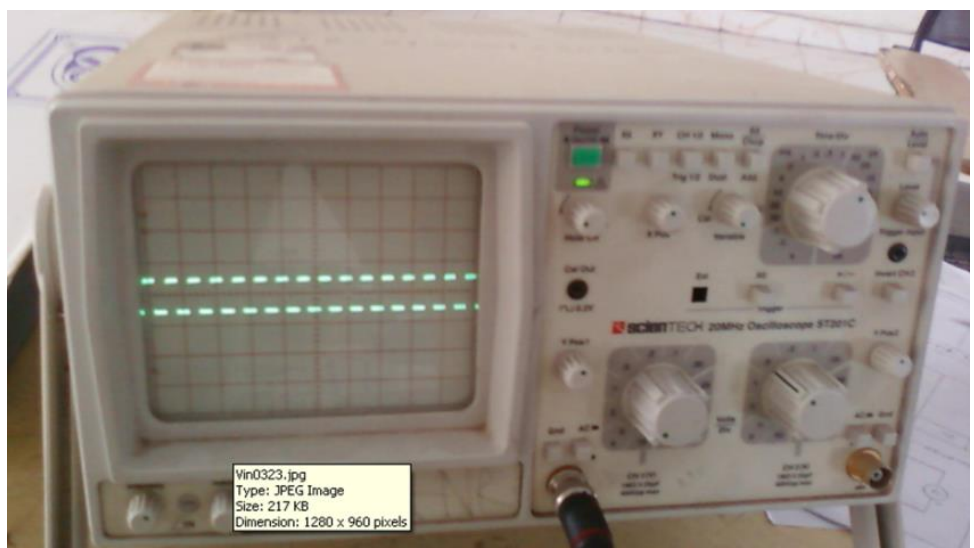

Fig. 21. Generated pulse from PIC controller

\section{Conclusion}

The proposed system utilizes a tertiary transformer winding that regenerates the transformer leakage reactances. There is flexibility in the control of the turn's ratio of the tertiary winding so that the snubber capacitor can be completely charged till it reaches the supply voltage. This 
gives a high degree of freedom in the control part. Due to this accidental changes in mode can be avoided. The proposed system offers a ZVS with a wide range of operating conditions which makes the circuit suitable for various applications

\section{References}

[1] C. Zhao, X. Wu, P. Meng and Z. Qian, "Optimum Design Consideration and Implementation of a Novel Synchronous Rectified Soft-Switched Phase-Shift Full-Bridge Converter for Low-OutputVoltage High-Output-Current Applications," in IEEE Transactions on Power Electronics, vol. 24, no. 2, pp. 388-397, Feb. 2009, doi: 10.1109/TPEL.2008.2005269.

[2] Leung-Pong Wong, D. K. -. Cheng, M. H. L. Chow and Yim-Shu Lee, "Interleaved three-phase forward converter using integrated transformer," in IEEE Transactions on Industrial Electronics, vol. 52, no. 5, pp. 1246-1260, Oct. 2005, doi: 10.1109/TIE.2005.855680.

[3] M. Jinno, "Efficiency improvement for SR forward converters with LC snubber," in IEEE Transactions on Power Electronics, vol. 16, no. 6, pp. 812-820, Nov. 2001, doi: $10.1109 / 63.974379$.

[4] T. Jin, K. Zhang, K. Zhang and K. Smedley, "A New Interleaved Series Input Parallel Output (ISIPO) Forward Converter With Inherent Demagnetizing Features," in IEEE Transactions on Power Electronics, vol. 23, no. 2, pp. 888-895, March 2008, doi: 10.1109/TPEL.2007.914813.

[5] C. D. Bridge, "Clamp voltage analysis for RCD forward converters," APEC 2000. Fifteenth Annual IEEE Applied Power Electronics Conference and Exposition (Cat. No.00CH37058), New Orleans, LA, USA, 2000, pp. 959-965 vol.2, doi: 10.1109/APEC.2000.822805.

[6] S. D. Johnson, A. F. Witulski and R. W. Erickson, "Comparison of resonant topologies in highvoltage DC applications," in IEEE Transactions on Aerospace and Electronic Systems, vol. 24, no. 3, pp. 263-274, May 1988, doi: 10.1109/7.192094.

[7] W. Zhang, Y. Lei, X. Zhang and Y. Liu, "Small Signal Analysis of a dual-switch forward Converter with non-ideal transformer in Current-Programmed Control," 2007 7th International Conference on Power Electronics and Drive Systems, Bangkok, 2007, pp. 49-52, doi: 10.1109/PEDS.2007.4487676.

[8] L. H. S. C. Barreto, A. A. Pereira, V. J. Farias, L. C. de Freitas and J. B. Vieira, "A boost converter associated with a new nondissipative snubber," APEC '98 Thirteenth Annual Applied Power Electronics Conference and Exposition, Anaheim, CA, USA, 1998, pp. 1077-1083 vol.2, doi: 10.1109/APEC.1998.654031. 